\title{
Mapping Spatial Variation of The Stomach, Esophageal and Lung Cancers and Their Shared Risk Factors in Iran at a County Level
}

\section{Shadi Ghasemi}

Isfahan University of Medical Sciences

\section{Emanuela Dreassi}

Universita degli Studi di Firenze

Saeedeh Aghamohammadi

Kerman University of Medical Sciences

Behzad Mahaki ( $\sim$ behzad.mahaki@gmail.com )

Isfahan University of Medical Sciences https://orcid.org/0000-0001-7062-6971

\section{Research}

Keywords: cancer mortality in Iran, stomach cancer, esophageal cancer, lung cancer, BYM model, shared component model.

Posted Date: August 24th, 2020

DOl: https://doi.org/10.21203/rs.3.rs-59536/v1

License: (9) This work is licensed under a Creative Commons Attribution 4.0 International License.

Read Full License 
ORIGINAL RESEARCH

2 Mapping Spatial Variation of the Stomach, Esophageal and Lung Cancers and Their Shared Risk

5 Shadi Ghasemi ${ }^{1,2}$

6 Emanuela Dreassi ${ }^{3}$

7 Saeedeh Aghamohammadi ${ }^{4}$

8 Behzad Mahaki²

9

10 'Student Research Committee, School of Health, Isfahan University of Medical Sciences,

11 Isfahan, Iran; ${ }^{2}$ Department of Biostatistics and Epidemiology, School of Health, Isfahan

12 University of Medical Sciences, Isfahan, Iran; ${ }^{3}$ Department of Statistics, Computer

13 Science, Applications (DiSIA), University of Florence, Florence, Italy; ${ }^{4}$ Iranian Ministry of

14 Health and Medical Education, Tehran, Iran.

Corresponding Author: Behzad Mahaki

$17 \quad$ Email: behzad.mahaki@gmail.com

$18 \quad$ Tel: +9809128077960 


\section{Abstract}

22 Background: Disease mapping has a long history in epidemiology. Evaluating the spatial pattern of several 23 diseases, as well as shared and specific risk factors in mortality, is considered as one of the applications 24 of disease mapping. Stomach, esophageal, and lung cancers are among the five most common cancers 25 among both genders in Iran, but no study is available on the spatial distribution of their mortality rate in Iran. 26 The present study aimed to investigate the geographical distribution of the relative risk of mortality and to 27 define the spatial pattern of shared and specific risk factors for the above-mentioned three cancers by 28 sharing their mortality data at the county level in Iran.

Method: This study analyzed the mortality data of stomach, esophageal, and lung cancers in Iran from March 2013 - March 2015. The Besag, York, and Mollie's (BYM) model and Shared Component (SC) models were used for investigating the spatial changes of cancer mortality and determining the spatial pattern of their shared and specific risk factors. Data analysis was conducted using $R$ and OpenBUGS software.

Results: The number of deaths for the esophageal, stomach, and lung cancers in Iran from March 2013 March 2014, was 11,720 of which stomach and lung cancers were $50 \%$ and $30 \%$, respectively. The spatial pattern of the stomach and esophageal cancer mortality was more similar to that of lung cancer due to the risk factors shared only between esophageal and stomach cancers.

Conclusion: The effects of smoking on lung cancer mortality were higher than the other two cancers. The available data indicated that esophageal cancer mortality was more affected by nutritional factors than stomach cancer mortality in Iran. The effect of nutritional factors on stomach and esophageal cancer mortality in the northern half of Iran was higher than the southern half. As a result, the relative risk of these cancers mortality in the southern half was more affected by smoking than nutritional factors.

43 Keywords: cancer mortality in Iran, stomach cancer, esophageal cancer, lung cancer, BYM model, shared component model. 
Introduction

49 With a long history in epidemiology disease mapping can identify risk factors and determine policies to

50 reduce mortality through recognizing the spatial patterns and high-risk areas of disease in a population (1,

51 2). Researchers have used univariate methods (single analysis for a single disease) and multivariate

52 (combined analysis of several diseases) to estimate more accurate spatial pattern of diseases during the

53 last few decades (3-5).

54 The spatial changes of diseases may be related to the differences in their risk factors. Disease mapping

55 allows us to evaluate the hypotheses about the cause of diseases (3). At the beginning, only univariate

56 methods were used for disease mapping. Then, the simultaneous statistical modeling of several diseases,

57 causing the identification of their shared and specific risk factors and more accurate results than single

58 analyses, was considered by researchers (6).

59 Evaluating the spatial pattern of several diseases, as well as shared and specific risk factors in mortality, is regarded as one of the applications of disease mapping $(3,6,7)$.

61 Cancer is one of the main public health problems in the world (8) and the second cause of mortality in Iran 62 after cardiovascular problems (9).

63 Identifying high-risk areas and the spatial distribution of risk factors is one of the required strategies for 64 controlling and implementing preventive policies to reduce the above-mentioned cancers (10). Stomach, 65 esophageal, and lung cancers are among the five most common cancers among both genders in Iran (9,

66 11, 12), but no study is available on their mortality in Iran at the county level. The present study aimed to 67 investigate the geographical distribution of the relative risk of mortality and determine the spatial pattern of 68 shared and specific risk factors for the above-mentioned three cancers by sharing their mortality data at the 69 county level in Iran. For this purpose, the model introduced by Besag, York and Mollie (BYM) (13) was used 70 for analyzing each cancer and determining their spatial pattern. The BYM model is one of the most widely 71 used disease mapping models where the spatial correlation of neighboring areas is considered. A 72 hypothesis states that the areas close to each other behave similarly in relation to the disease (13). In 
73

74

addition, shared components (SC) model (4) was used for highlighting the similarity and non-similarity of spatial patterns of stomach, esophageal, and lung cancers mortality in the counties of Iran due to shared and specific risk factors. Such a model has been used in several studies for determining the spatial changes of risk factors in some diseases $(7,14,15)$. In this case, counts of stomach, esophageal, and lung cancers mortality refer to the variables of the model response with a shared risk factor (smoking (16-18)) and the other risk factor, i.e. nutritional factors $(16-18)$ is shared only between esophageal cancer and stomach cancers. In this model, latent variables are used as substitutes for risk factors $(4,7)$. In addition, a random effect is used as a model predictor to consider the probable other risk.

\section{Materials and method}

\section{Data}

In this study, the data of esophageal (ICD10 code C15), stomach (C16), and lung (C33-C34) cancers mortality in 375 counties of Iran were considered from March 2013-March 2015 and were collected by the Network Management Center of Iranian Ministry of Health and Medical Education (19) and were classified by county. Also population at risk was used to compute expected number of cases for each county and cancer.

According to the previous study about risk factors of the esophagus, stomach and lung cancers, we considered smoking as a common risk factor for these cancers and nutritional factor as common risk factor just for esophagus and stomach cancer in the model. This study was confirmed by the Ethical Committee of Isfahan University of Medical Sciences (IR.MUI.REC.1395.3.687).

\section{Model}

Assume $y_{i j}$ represents the number of deaths for the $i$-th county $(i=1,2, \ldots, 375)$ and the $j$-th cancer $(j=1,2,3)$. In addition, assume that $y_{\mathrm{ij}}$ has a Poisson distribution with parameters $E_{\mathrm{ij}} \theta_{\mathrm{ij}}$ where $\mathrm{E}_{\mathrm{ij}}$ indicates the expected mortality rate in the $\mathrm{i}$-th county due to the $\mathrm{j}$-th cancer and $\theta_{\mathrm{ij}}$ represents a real relative risk $(\mathrm{RR})$ unknown for the $\mathrm{j}$-th cancer in the i-th county.

The BYM model was used for fitting the spatial pattern of each cancer. This model is one of the most widely used models in disease mapping where the spatial correlation structure of data is considered for obtaining more reliable estimates. In this structure, the data of neighboring counties is shared. In this structure, two 
counties that have at least one common border are considered neighbors. In the BYM logarithm model, the relative risk for the $\mathrm{j}$-th cancer and the $\mathrm{i}$-th county $\left(\theta_{\mathrm{ij}}\right)$ is modeled as follows:

$$
\log \left(\theta_{i j}\right)=\alpha_{j}+u_{i j}+\square_{i j}
$$

where $\alpha_{\mathrm{j}}$ is the average mortality rate in all counties for the $\mathrm{j}$-th cancer. For each cancer, $\mathrm{u}_{\mathrm{i}}$ and $\square_{\mathrm{i}}$ are the random variables being given in the model to consider structured and unstructured spatial changes. It is assumed that $u_{i}$ follow a normal distribution with mean equal to the average of the neighbor's number and variance inversely proportional to the number of these neighbors and also $\square_{i}$ has a normal distribution with mean zero and variance $\sigma^{2}(13)$.

Then, the Bayesian shared component model was used to determine the distribution of risk factors (4). Based on the previous studies on the risk factors of esophageal, stomach and lung cancers, smoking (1618) was considered in this model as a shared risk factor for the three cancers and nutrition as a shared risk factor for both esophageal and stomach cancers. The SC model is a generalization of the BYM model and one of its advantages is using latent variables as substitutes for risk factors without having relevant data $(7,20)$.

Similar to the BYM model, it is assumed here that risk logarithm is a function of random components:

$$
\begin{gathered}
\log \left(\theta_{i 1}\right)=\alpha_{1}+u s_{i} \times w_{1}+u a_{i} \times \delta_{1}+\square_{i 1} \\
\log \left(\theta_{i 2}\right)=\alpha_{2}+u s_{i} \times w_{2}+u a_{i} \times \delta_{2}+\square_{i 2} \\
\log \left(\theta_{i 3}\right)=\alpha_{3}+u s_{i} \times w_{3}+\square_{i 3}
\end{gathered}
$$

where $\alpha_{3}$ is defined like the BYM model. $\theta_{\mathrm{i} 1}, \theta_{\mathrm{i} 2}$, and $\theta_{\mathrm{i} 3}$ represent the relative risk of esophageal, stomach, and lung cancer in the $\mathrm{i}$-th county, respectively. $\mathrm{us}_{\mathrm{i}}$ and $\mathrm{ua}_{\mathrm{i}}$ are the latent random variables being respectively substitute for the shared risk factor of three cancers (smoking) and the shared risk factor for esophageal and stomach cancers (nutritional factor) which both follow some conditional autoregressive (CAR) normal distribution to include the spatial correlation of the data.

$$
\left[u s_{i} \mid u s_{j}, i \neq j, \square_{u s}\right] \sim N\left(\overline{u s}_{i},\left(\square_{u s} \sum_{j} w_{i j}\right)^{-1}\right)
$$




$$
\begin{gathered}
{\left[u a_{i} \mid u a_{j}, i \neq j, \square_{u a}\right] \sim N\left(\overline{u a}_{i},\left(\square_{u a} \sum_{j} w_{i j}\right)^{-1}\right)} \\
\overline{u s}_{i}=\frac{1}{\sum_{j} w_{i j}} \sum_{j} u s_{j} w_{i j} \quad, \quad \overline{u a}_{i}=\frac{1}{\sum_{j} w_{i j}} \sum_{j} u a_{j} w_{i j}
\end{gathered}
$$

$126 w_{i j}$ is the weight for the adjacency and $w_{i j}=1$ if $i$ and $j$ are adjacent and 0 otherwise. The adjacency is 127 herein defined as having at least one common border $(13,21)$. In addition, the parameters $\lambda_{u s}$ and $\lambda_{u a}$ are 128 precision parameters and are supposed to follow the Gamma $(0.5,0.0005)$ distribution function (22).

$129 \mathrm{w}$ and $\delta$ are the unknown parameters being considered for estimating the effect of each risk factor on the 130 relative risk of diseases and assuming that their logarithm has a normal distribution.

$131 \square_{\mathrm{ij}}$ represents the specific heterogeneity effects of disease and is included in the model to consider the 132 probable changes which are not explained by the risk factors and are assumed to have a normal distribution $133(3,4)$.

134 In this study, WinBUGS software version 1.4.3 and MCMC method were used for obtaining the posterior 135 distributions and estimates of parameters. In this method, the first 50000 repetitions were discarded and 136 then 2500 samples of the subsequent 200,000 iterations were stored at the spacing of 80 iterations. 137 Algorithm convergence was evaluated using the Gelman- Rubin test (23). Finally, the maps were drawn 138 using version 3.6.1 of $\mathrm{R}$ software.

\section{Results}

140 The number of recorded mortality due to esophageal, stomach, and lung cancers in Iran during March 2013 141 - March 2014 was 11,720 of which stomach and lung cancers were 50 and $30 \%$, respectively. The results 142 of the BYM model for single analyses are presented in Figure 1. Northeastern and northwestern regions 143 were at higher risk for esophageal cancer mortality. However, the risk of stomach cancer mortality was high 144 in the northern and western regions in addition to northeastern and northwestern regions. The dispersion 145 of the relative risk of lung cancer mortality was higher than the other two cancers, so that other regions, 146 except for the southeastern region, had almost an average risk. Single analysis maps indicated a shared 147 spatial pattern for the relative risk of mortality by three cancers, especially in the northwestern and 
southeastern regions which can be related to the shared risk factors between the three diseases (smoking). As observed, the similarity between the spatial pattern of stomach and esophageal cancer mortality was higher than that of lung cancer due to the shared risk factors between esophageal and stomach cancers. The relative risk for esophageal and stomach cancers was significantly higher in the northern half of Iran than the southern half. However, the dispersion of the relative risk of lung cancer was higher than the other two cancers.

In addition, estimating the effects of shared and specific risk factors for the studied cancers is mapped in Figure 2. Smoking changes were more than nutritional factors and had the highest effect in the northwestern region and average effect in other regions except the southeastern regions. However, the effect of the nutrition was significantly higher in the northern half than the southern half. Accordingly, Iran was classified into two regions of low-risk and high-risk. The maximum effect of this factor was in the northeastern and northwestern regions and part of the north of Iran.

Table 1 indicates the relative weight of each risk factor derived from the SC model. The posterior mean of scale parameters is related to the shared factor of smoking $w_{1}=0.72, w_{2}=0.93$ and $w_{3}=1.47$. The values $w_{2} / w_{1}=1.29, w_{3} / w_{2}=1.58$ and $w_{3} / w_{1}=2.04$ indicated that the effect of smoking on stomach cancer is slightly more than esophageal cancer while its effect on lung cancer is more than stomach and esophageal cancers. In addition, the posterior mean for the parameters related to nutrition for esophageal and stomach cancers were obtained at 1.82 and 0.70 , respectively. The available data indicated that esophageal cancer mortality was more affected by nutrition than stomach cancer mortality in Iran $\left(\delta_{1} / \delta_{2}=\right.$ 2.6).

Table 2 provides the ranking according the mean value RR of the counties of each province (each province includes several county, as shown in Figure 3) for each cancer. The highest mortality rate for esophageal, stomach and lung cancers were in Ardabil, Zanjan and West Azerbaijan provinces, respectively.

Furthermore, Table 3 indicates the ranking of provinces based on the mean estimated effect of the two risk factors. The highest ranking in the effect of smoking and nutritional factors is related to West Azerbaijan and Ardabil provinces (northwestern Iran), respectively. 
175 Figure 1. Maps of the estimated relative risk in the BYM model for Esophagus (A), Stomach (B) and Lung (C) cancer

176 mortality in Iran.

177

178

179

180

181

182

183

184

185

186

187

188

189

190

191

192

\section{4}

Table 1. Posterior median and $95 \% \mathrm{Cls}$ for weights of three cancers in the shared component model

Table 1. Posterior median and 95\% Cls for weights of three cancers in the shared component model
\begin{tabular}{|l|l|c|c|}
\hline Risk Factors & Cancer & Median & $95 \% \mathbf{C l}$ \\
\hline \multirow{3}{*}{ Smoking } & Esophagus & 0.72 & $0.43-1.23$ \\
\cline { 2 - 4 } & Stomach & 0.93 & $0.57-1.42$ \\
\cline { 2 - 4 } & Lung & 1.47 & $0.79-2.33$ \\
\hline \multirow{2}{*}{ Nutritional Factors } & Esophagus & 1.82 & $0.90-3.20$ \\
\cline { 2 - 4 } & Stomach & 0.70 & $0.36-1.27$ \\
\hline
\end{tabular}

85

Figure 2 Shared risk in three cancers mortality (Smoking) (A) and specific risk for Esophagus and Stomach cancers (Nutritional Factors) (B) from SC model, in Iran.
Figure 3. The Provinces of Iran 
193 Table 2. Relative risk of Esophagus, Stomach and Lung cancer in Iranian provinces.

\begin{tabular}{|c|c|c|c|c|c|c|c|c|c|c|c|c|}
\hline \multirow[t]{2}{*}{ Province } & \multicolumn{4}{|c|}{ Esophagus } & \multicolumn{4}{|c|}{ Stomach } & \multicolumn{4}{|c|}{ Lung } \\
\hline & Rank & $\begin{array}{l}\text { High } \\
\text { risk }\end{array}$ & $\begin{array}{c}\text { Some } \\
\text { risk }\end{array}$ & $\begin{array}{l}\text { Low } \\
\text { risk }\end{array}$ & Rank & $\begin{array}{l}\text { High } \\
\text { risk }\end{array}$ & $\begin{array}{l}\text { Some } \\
\text { risk }\end{array}$ & $\begin{array}{l}\text { Low } \\
\text { risk }\end{array}$ & Rank & $\begin{array}{l}\text { High } \\
\text { risk }\end{array}$ & $\begin{array}{l}\text { Some } \\
\text { risk }\end{array}$ & $\begin{array}{l}\text { Low } \\
\text { risk }\end{array}$ \\
\hline Alborz & 19 & & & * & 17 & & * & & 15 & & * & \\
\hline Ardabil & 1 & * & & & 4 & * & & & 13 & & * & \\
\hline Bushehr & 27 & & & * & 27 & & & * & 18 & & * & \\
\hline Chaharmahal Bakhtiari & 26 & t & & * & 15 & . & * & & 25 & & & * \\
\hline East Azerbaijan & 3 & * & & & 2 & * & & & 2 & * & & \\
\hline Fars & 25 & & & * & 23 & & & * & 26 & & & * \\
\hline Gilan & 14 & & * & & 7 & * & & & 5 & * & & \\
\hline Golestan & 7 & * & & & 21 & & * & & 29 & & & * \\
\hline Hamadan & 18 & & & * & 13 & * & & & 11 & & * & \\
\hline Hormozgan & 30 & & & * & 29 & & & * & 28 & & & * \\
\hline Ilam & 15 & & * & & 9 & * & & & 23 & & & * \\
\hline Isfahan & 21 & & & * & 20 & & * & & 6 & & * & \\
\hline Kerman & 28 & & & * & 28 & & & * & 20 & & * & \\
\hline Kermanshah & 13 & & * & & 22 & & * & & 12 & & * & \\
\hline Khorasan Razavi & 6 & * & & & 5 & * & & & 3 & * & & \\
\hline Khorasan North & 4 & * & & & 11 & * & & & 21 & & * & \\
\hline Khorasan South & 10 & * & & & 18 & & * & & 9 & & * & \\
\hline $\begin{array}{l}\text { Kohgiluyeh } \\
\text { Buyerahmad }\end{array}$ & 24 & & & * & 19 & & * & & 27 & & & * \\
\hline Khuzestan & 23 & & & * & 26 & & & * & 24 & & & * \\
\hline Kurdistan & 5 & * & & & 6 & * & & & 4 & * & & \\
\hline Lorestan & 12 & & * & & 12 & * & & & 19 & & * & \\
\hline Mazandaran & 8 & * & & & 8 & * & & & 8 & & * & \\
\hline Markazi & 20 & & & * & 10 & * & & & 10 & & * & \\
\hline Qom & 16 & & * & & 24 & & & * & 22 & & & * \\
\hline Qazvin & 17 & & * & & 14 & & * & & 16 & & * & \\
\hline Semnan & 9 & * & & & 16 & & * & & 14 & & * & \\
\hline Sistan Baluchestan & 29 & & & * & 30 & & & * & 30 & & & * \\
\hline West Azerbaijan & 2 & * & & & 3 & * & & & 1 & * & & \\
\hline Yazd & 22 & & & * & 25 & & & * & 7 & & * & \\
\hline Zanjan & 11 & & * & & 1 & * & & & 17 & & * & \\
\hline
\end{tabular}

194

195 
Table 3. Relative risk of smoking and nutritional factors in Iranian provinces.

\begin{tabular}{|c|c|c|c|c|c|c|c|c|}
\hline \multirow[t]{2}{*}{ Province } & \multicolumn{4}{|c|}{ Smoking } & \multicolumn{4}{|c|}{ Nutritional Factors } \\
\hline & Rank & High risk & $\begin{array}{c}\text { medium } \\
\text { risk }\end{array}$ & Low risk & Rank & High risk & $\begin{array}{c}\text { medium } \\
\text { risk }\end{array}$ & Low risk \\
\hline Alborz & 14 & & * & & 19 & & * & \\
\hline Ardabil & 11 & & * & & 1 & * & & \\
\hline Bushehr & 19 & & * & & 28 & & & * \\
\hline Chaharmahal Bakhtiari & 22 & & * & & 24 & & & * \\
\hline East Azerbaijan & 2 & * & & & 4 & * & & \\
\hline Fars & 26 & & * & & 26 & & & * \\
\hline Gilan & 5 & * & & & 15 & & * & \\
\hline Golestan & 28 & & & * & 7 & * & & \\
\hline Hamadan & 12 & & * & & 18 & & * & \\
\hline Hormozgan & 29 & & & * & 30 & & & * \\
\hline Ilam & 20 & & * & & 10 & * & & \\
\hline Isfahan & 7 & & * & & 21 & & * & \\
\hline Kerman & 25 & & * & & 29 & & & * \\
\hline Kermanshah & 17 & & * & & 14 & & * & \\
\hline Khorasan Razavi & 3 & * & & & 5 & * & & \\
\hline Khorasan North & 23 & & * & & 2 & * & & \\
\hline Khorasan South & 10 & & * & & 13 & * & & \\
\hline Kohgiluyeh Buyerahmad & 24 & & * & & 23 & & & * \\
\hline Khuzestan & 27 & & * & & 25 & & & * \\
\hline Kurdistan & 4 & * & & & 6 & * & & \\
\hline Lorestan & 15 & & * & & 12 & * & & \\
\hline Mazandaran & 8 & & * & & 9 & * & & \\
\hline Markazi & 6 & & * & & 20 & & * & \\
\hline Qom & 21 & & * & & 17 & & * & \\
\hline Qazvin & 16 & & * & & 16 & & * & \\
\hline Semnan & 18 & & * & & 11 & * & & \\
\hline Sistan Baluchestan & 30 & & & * & 27 & & & * \\
\hline West Azerbaijan & 1 & * & & & 3 & * & & \\
\hline Yazd & 13 & & * & & 22 & & & * \\
\hline Zanjan & 9 & & * & & 8 & * & & \\
\hline
\end{tabular}

Discussion

200 In this study, single analyses were used to obtain the geographical distribution of the relative risks for

201 stomach, esophagus and lung cancers mortality. Then, the shared component model was used for

202 evaluating the pattern of shared and specific risk factors for stomach, esophagus and lung cancers.

203 Estimating the effect of shared and specific risk factors on mortality, without having real data, is considered

204 as one of the features of the SC model with latent variables (as substitutes to risk factors). 
Based on the results, the effect of the shared risk factor (smoking) on lung cancer mortality was higher than the other two cancers. Smoking has a higher prevalence than nutritional factors and has a high effect in other places except in southeastern Iran. The effect of nutritional factors, which was considered as a shared risk factor between stomach and esophageal cancer mortality in this study, was higher than the effect of esophageal cancer on stomach cancer mortality.

The results indicated that the effect of nutritional factors on stomach and esophageal cancers mortality in the northern half of Iran was more than the southern half and the relative risk of mortality in the southern half was more affected by smoking than nutritional factors. East Azerbaijan and West Azerbaijan in northwestern Iran had a high ranking among the other provinces in terms of the effect of both risk factors. The above-mentioned two provinces had high rates of mortality from the three cancers, which can be attributed to the interaction of smoking and nutrition.

The results obtained in this study are consistent with the results of previous studies $(7,24-27)$. Mahaki et al. (7) used the SC model to investigate the shared and specific risk factors for seven cancers at the provincial level. Although the present study had some similar results, it had some differences such as the distribution of smoking. Since each province includes several counties, estimates of the relative risk of the provinces are strongly influenced by counties with the very high relative risk or very low relative risk. In addition, the low consumption of fruits and vegetables was considered as a shared risk factor for stomach and esophageal cancers, while most high-risk areas had appropriate and easier access to fruits and vegetables than other places, especially the deserts of Iran. Therefore, nutritional factors were considered as a shared risk factor for these two cancers. Nutritional factors such as the low consumption of fruits and vegetables $(28,29)$, consumption of tea and hot food $(29,30)$, consumption of salty foods $(29,31)$, excessive consumption of red meat $(27,28)$, and Selenium deficiency $(30,32)$, can be regarded as one of the most significant factors in effective nutrition in the incidence of stomach and esophageal cancers.

Regarding the limitations of the present study, the access to data about Tehran province was not plausible in this study. Thus, this province was excluded from the study.

\section{Conclusions}


Based on the obtained data, no study was available on stomach, esophageal and lung cancers mortality in Iran. Using data at the county level instead of the province level in a multivariate spatial model was one of the significant advantages of this study over other studies dealing with the geographical distribution of diseases in Iran. Evaluating data at the county level provided more accurate and detailed data about their status than the provincial level and could help planning and making policies more effectively. Considering data on a larger scale sometimes ignores data at a smaller area and county level. In the present study, Isfahan province was identified as a low-risk province in terms of esophageal cancer mortality (Table 2), while Khor and Biyabank County in this province had very high esophageal cancer mortality.

\section{Competing interests}

The authors of this article declare that they have no conflict of interests.

\section{Acknowledgments}

242 The authors are grateful to express their sincere thanks to the department of information and statistics network of Education Medical and Health, Iran. This article was supported by a grant [395687] from Isfahan University of Medical Sciences, Isfahan, Iran.

\section{References}

247 1. Lawson $A B$, Biggeri $A B$, Boehning $D, E$ Lr, Viel J-F, Clark P, et al. Disease mapping models: an empirical evaluation. Statistics Med. 2000;19:2217-41.

2. Walter SD. Disease mapping: A historical perspective. In: Elliott P, Wakefield JC, Best NG, Briggs DJ, editors. Spatial Epidemiology: Methods and Applications. 15: Oxford: Oxford University Press; 2000. p. 223-39.

3. Dreassi E. Polytomous disease mapping to detect uncommon risk factors for related diseases. Biometrical Journal: Journal of Mathematical Methods in Biosciences. 2007;49(4):520-9.

4. Held L, Natário I, Fenton SE, Rue H, Becker N. Towards joint disease mapping. Statistical Methods in Medical Research. 2005;14(1):61-82.

5. Lawson AB, Browne WJ, Rodeiro CL. Disease Mapping With WinBUGS and MLwiN. Hoboken, NJ, USA: John Wiley \& Sons; 2003

6. Nasrazadani M, Maracy MR, Dreassi E, Mahaki B. Mapping of stomach, colorectal, and bladder cancers in Iran, 2004-2009: Applying Bayesian polytomous logit model. Int J Prev Med. 2018;9:104.

7. Mahaki B, Mehrabi Y, Kavousi A, Akbari ME, Waldhoer T, Schmid VJ, et al. Multivariate disease mapping of seven prevalent cancers in Iran using a shared component model. Asian Pac J Cancer Prev. 2011;12:2353-8. 
8. Siegel RL, Miller KD, Jemal A. Cancer statistics, 2019. CA Cancer J Clin. 2019;69(1):7-34.

9. Khosravi A, Aghamohammadi S, Kazemi E. Mortality Profile in the Islamic Republic of Iran 2015 (20 leading cause of death by sex and age group).Ministry of Health and Medical Education. Tehran. Iran, 2015:3.

10. Shibuya K, Mathers CD, Boschi-Pinto C, Lopez AD, Murray CJ. Global and regional estimates of cancer mortality and incidence by site: II. Results for the global burden of disease 2000. BMC cancer. 2002;2(1):37.

11. Kolahdoozan S, Sadjadi A, Radmard AR. Five common cancers in Iran. Arch Iran Med. 2010;13:1436.

12. Mohebbi E, Nahvijou A, Hadji M, Rashidian H, Seyyedsalehi MS, Nemati S, et al. Iran Cancer Statistics in 2012 and Projection of Cancer Incidence by 2035. Basic \& Clinical Cancer Research. Basic \& Clinical Cancer Research. 2017;9(3):3-22.

13. Besag J, York J, A M. Bayesian image restoration with two applications in spatial statistics. Ann Inst Stat Math. 1991;43:1-59.

14. Ahmadipanahmehrabadi V, Hassanzadeh A, Mahaki B. Bivariate spatio-temporal shared component modeling: Mapping of relative death risk due to colorectal and stomach cancers in Iran provinces. Int J Prev Med 2018;9. [In Press].

15. Raei M, Schmid VJ, Mahaki B. Bivariate spatiotemporal disease mapping of cancer of the breast and cervix uteri among Iranian women. Geospatial Health. 2018;13(1):164-71.

16. González CA, Pera G, Agudo A, Palli D, Krogh V, Vineis P, et al. Smoking and the risk of gastric cancer in the European Prospective Investigation Into Cancer and Nutrition (EPIC). Int J Cancer. 2003;107:629-34.

17. O'Keeffe LM, Taylor G, Huxley RR, Mitchell P, Woodward M, Peters SA. Smoking as a risk factor for lung cancer in women and men: a systematic review and meta-analysis. BMJ open. 2018;8(10):e021611.

18. Torre LA, Siegel RL, Ward EM, Jemal A. Global cancer incidence and mortality rates and trends-an update. Cancer Epidemiol Biomarkers Prev. 2016;25:16-27.

19. Aghamohamadi S, Khosravi A, Kazemi E, Shariati M. Mortality profile in the Islamic Republic of Iran from 2012 to 2015. Tehran: Ministry of Health and Medical Education. 2018.

20. Mahaki B, Mehrabi Y, Kavousi A, Schmid VJ. Joint Spatio-Temporal Shared Component Model with an Application in Iran Cancer Data. Asian Pac J Cancer Prev. 2018;19:1553-60.

21. Earnest A, Morgan G, Mengersen K, Ryan L, Summerhayes R, Beard J. Evaluating the effect of neighbourhood weight matrices on smoothing properties of Conditional Autoregressive (CAR) models. Int J Health Geogr. 2007;6(1):54.

22. Kelsall J, Wakefield J. Discussion of 'Bayesian models for spatially correlated disease and exposure data', by Best et al. Bayesian statistics. 1999;6:151.

23. Gelman A, Rubin DB. Inference from iterative simulation using multiple sequences. Statistical science. 1992;7(4):457-72.

24. Asmarian N, Jafari-Koshki T, Soleimani A, Ayatollahi SMT. Area-to-area poisson kriging and spatial bayesian analysis in mapping of gastric cancer Incidence in Iran. Asian Pac J Cancer Prev. 2016;17(10):4587-90.

25. Pakzad R, Khani Y, Pakzad I, Momenimovahed Z, Mohammadian-Hashejani A, Salehiniya H, et al. Spatial analysis of stomach cancer incidence in Iran. Asian Pac J Cancer Prev. 2016;17(S3):27-32.

26. Rastaghi S, Jafari-Koshki T, Mahaki B. Application of Bayesian multilevel space-time models to study relative risk of esophageal cancer in Iran 2005-2007 at a county level. Asian Pac J Cancer Prev. 2015;16(14):5787-92. 
27. Soleimani A, Hassanzadeh J, Ghanbari Motlagh A, Tabatabaee H, Partovipour E, Keshavarzi S, et al. Spatial analysis of common gastrointestinal tract cancers in Counties of Iran. Asian Pac J Cancer Prev. 2015;16:4025-9.

28. Malekzadeh R, Derakhshan MH, Malekzadeh Z. Gastric cancer in Iran: epidemiology and risk factors. Arch Iran Med. 2009;12:576-83.

29. Pourfarzi F, Whelan A, Kaldor J, Malekzadeh R. The role of diet and other environmental factors in the causation of gastric cancer in Iran - a population based study. Int J Cancer. 2009;125:1953 -60 .

30. Sadjadi A, Marjani H, Semnani SH, Nasseri-Moghaddam S. Esophageal cancer in Iran: A Review. MEJC. 2010;1:5-14.

31. Ghadimi R, Taheri H, Suzuki S, Kashifard M, Hosono A, Esfandiary I, et al. Host and environmental factors for gastric cancer in Babol, the Caspian Sea Coast, Iran. Eur J Cancer Prev. 2007;16:192 5.

32. Nouraie M, Pourshams A, Kamangar F, Sotoudeh M, Derakhshan MH, Akbari MR, et al. Ecologic study of serum selenium and upper gastrointestinal cancers in Iran. World J Gastroenterol. 2004;10:2544-6. 


\section{Figures}
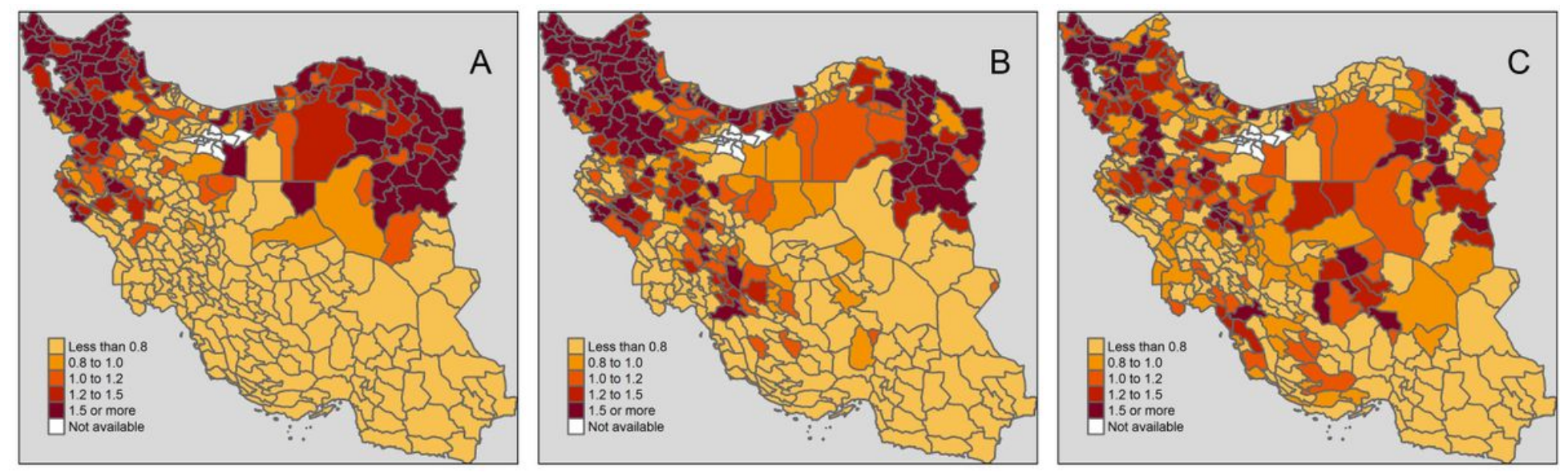

\section{Figure 1}

Maps of the estimated relative risk in the BYM model for Esophagus (A), Stomach (B) and Lung (C) cancer mortality in Iran. Note: The designations employed and the presentation of the material on this map do not imply the expression of any opinion whatsoever on the part of Research Square concerning the legal status of any country, territory, city or area or of its authorities, or concerning the delimitation of its frontiers or boundaries. This map has been provided by the authors.
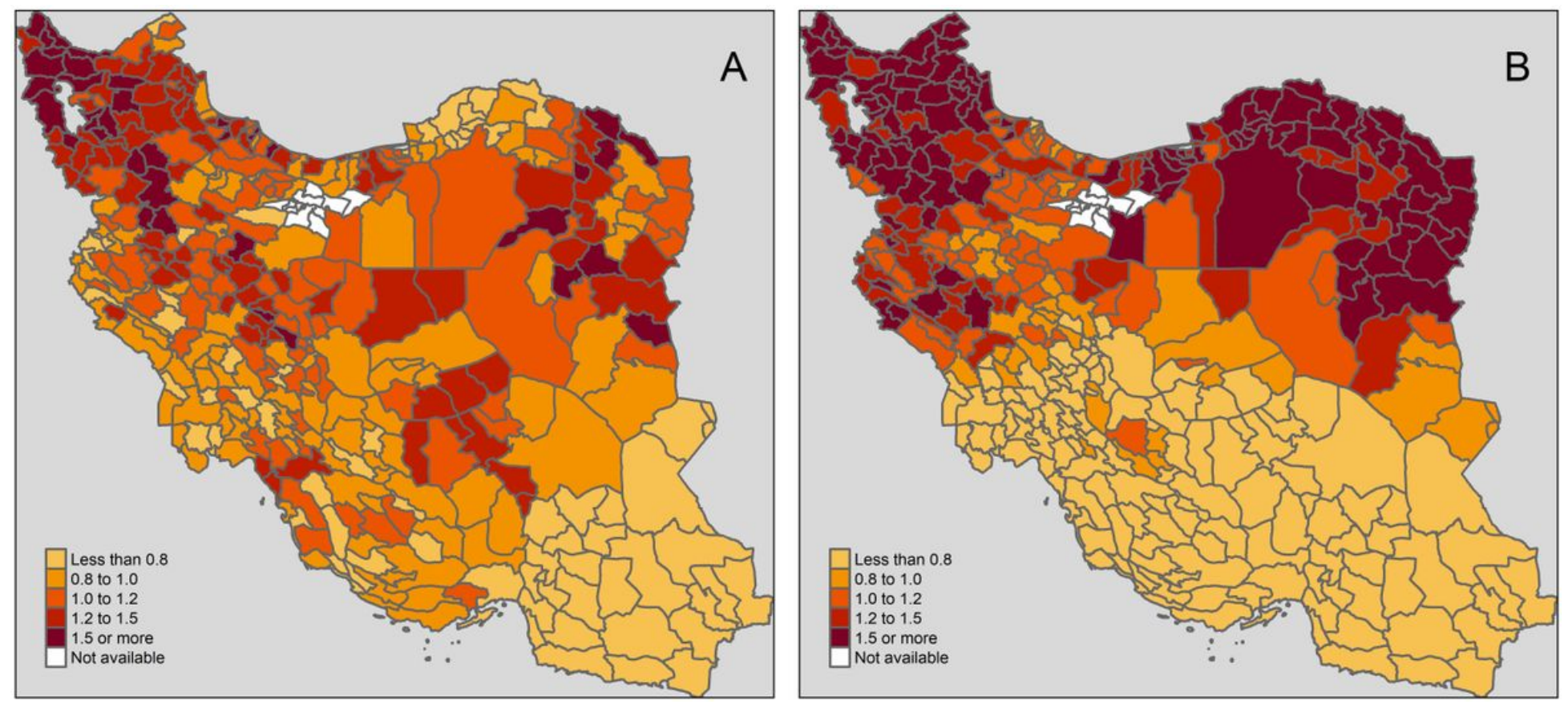

\section{Figure 2}

Shared risk in three cancers mortality (Smoking) (A) and specific risk for Esophagus and Stomach cancers (Nutritional Factors) (B) from SC model, in Iran. Note: The designations employed and the presentation of the material on this map do not imply the expression of any opinion whatsoever on the part of Research Square concerning the legal status of any country, territory, city or area or of its 
authorities, or concerning the delimitation of its frontiers or boundaries. This map has been provided by the authors.

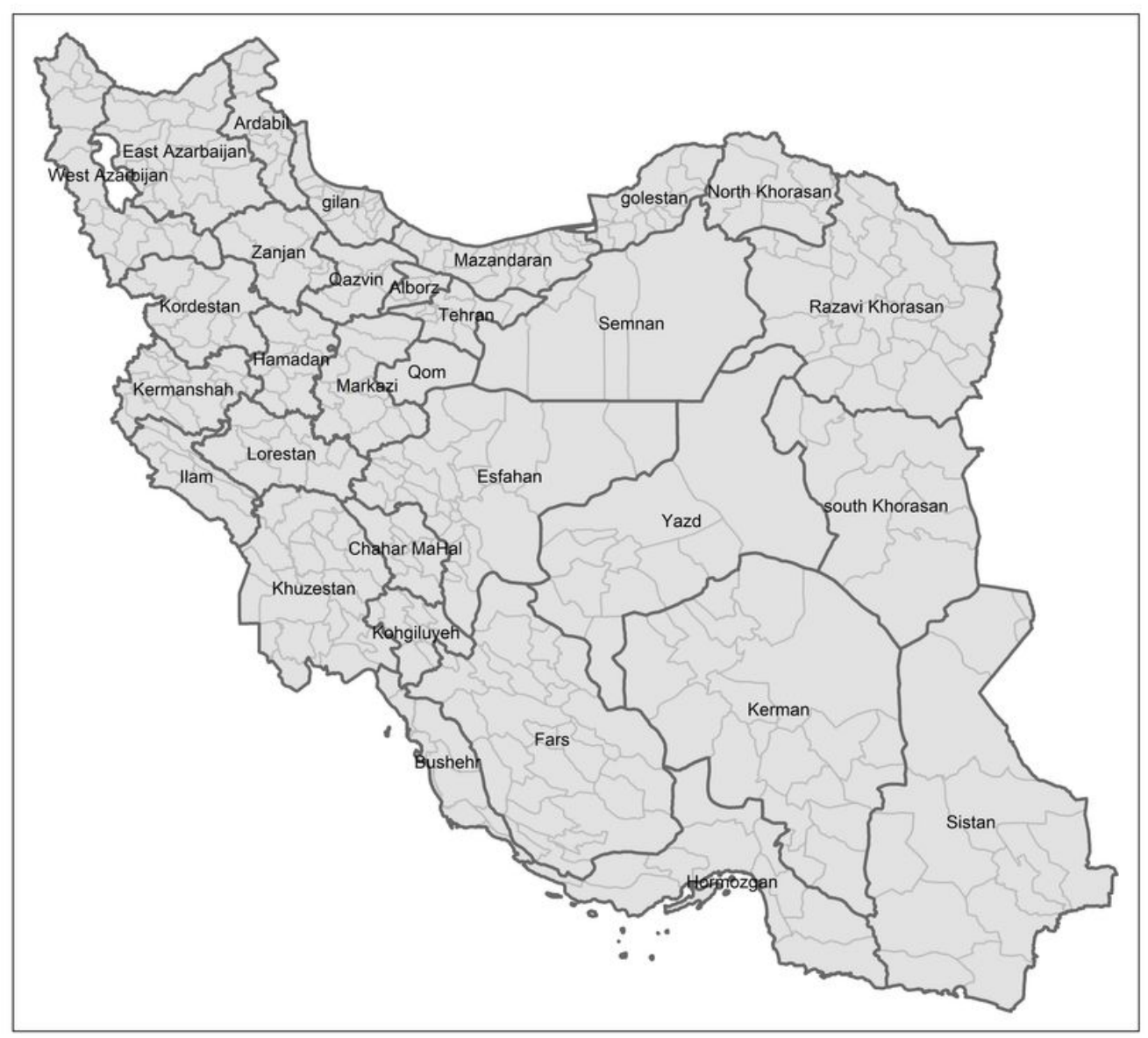

\section{Figure 3}

The Provinces of Iran Note: The designations employed and the presentation of the material on this map do not imply the expression of any opinion whatsoever on the part of Research Square concerning the legal status of any country, territory, city or area or of its authorities, or concerning the delimitation of its frontiers or boundaries. This map has been provided by the authors. 